\title{
ANALYSIS OF ITEMS OF SUSTAINABLE QUALITY OF LIFE CONCEPT BASED ON EXTENDED LINEAR MULTI-REGRESSION MODEL
}

\author{
Gordana Todorović* \\ The municipality of the city of Kragujevac, Kragujevac, Serbia \\ Ivan Savović \\ Center for Quality, Faculty of Engineering, University of Kragujevac, Serbia \\ Aleksandar Đorđević \\ Center for Quality, Faculty of Engineering, University of Kragujevac, Serbia
}

In this paper, an extended multi-regression model for determining strength relation among dimensions of sustainable development and quality of life in section of communal services in urban areas is developed. The relative importance of dimensions of sustainable development is stated by pairwise comparison matrix. The values of dimensions of sustainable development and quality of life are assessed by decision makers. Judgments of decision makers are mapped into common measurement scale. The weighted values of sustainable development dimensions are calculated as product of their weights and assessed values. The assessed values of quality life are depended variable in the proposed linear multi-regression model. By using standard statistical software, partial correlation coefficients are given. The proposed linear multi-regression model is illustrated by example with real life data.

Key words: Sustainable development; Quality of life; Assessment; Sustainable use

\section{INTRODUCTION}

Changes in the world, above all in the domain of politics, the economy, demography, and environment, demand the continuous improvement of sustainable development concept. This concept can be defined as development and obtainment of resources to meet human needs in the present and for future generations to come. Sustainable development involves economic prosperity, environmental quality, social equality, culture, etc [14]. The sustainable development concept should be considered as technocratic concept. On other hand, the quality of life concept is based on idea that in order to wish something, we have to be touched in our hearts [07]. According to relevant literature, the sustainable development can be described through many dimensions. In the quality of life concept, the opportunities are provided to meet human needs in the forms of built human, social, and natural capital. The quality of life concept includes many different factors. In the literature, there are many research studies in which dimensions and factors are described. Also, many researchers tried to determine the level of sustainable development and quality of life at the level of complex organization systems.

Motivation for this research comes from the fact that there are no research papers that treat exact methods in the context of the sustainable development and quality of life dimensions - an assessment of dimensions of sustainable development, an assessment factor of quality of life business and their improvement. According to results of good practice, it is known that it is almost impossible to enhance all sustainable development dimensions at the same time, having in mind overall complexity and definite resources - costs, time, human resources, etc. Enhancement activities are based on the already defined relationship strengths among sustainable development dimensions and quality of life in communal services sector. The sustainable development in different levels and different sectors may be described by different dimensions. The dimensions of sustainable development may vary depending on the standards related to considered sectors and treated level of consideration, etc. Similarity, quality of life consists of factors which 
are defined by different aspects. It can be said that sustainable development dimensions and factors of quality of life have complex hierarchical structure and there are numerous relations among them. In compliance with this assumption, it can be said that problem of correlations determination among sustainable development dimensions and factors of quality of life can be stated as a multi-regression problem.

The wider objective of this research may be interpreted as an integration of the sustainable development concept, quality of life concept, multicriteria optimization methods and regression analysis. The mentioned integration includes: a) presentation of a sustainable development at the communal services sector level as a set of different dimensions; b) the assessment of the relative importance of sustainable development dimensions by Analytic Hierarchy Process (AHP) [17]; c) definition of linear multi-regression model among sustainable development dimensions and quality of life; d) definition of management initiatives which should lead to the improvement of sustainable development dimensions; the order of taking management initiatives is based on the obtained coefficient correlation values.

The main contribution of the proposed model, by its application, is that the strength of the connections between the sustainable development dimensions and quality of life in communal services sector are obtained.

This paper is organized in the following way: in Section 2, the brief retrospective terms such as sustainable development and quality of life are presented. In Section 3 the model which is used to describe relations among sustainable development dimensions and factors of quality of life at the level communal services processes is proposed. The proposed model is illustrated by real life data which came from communal enterprises, in the section 4. Discussion of obtained results is predented in section 5 . The conclusion is presented in Section 6 .

\section{EVALUATION FRAMEWORK}

In this Section, the basic consideration of two concepts is presented. In this paper, broader model of sustainable development concept and quality of life concept integration in communal services sector is proposed. The proposed mod$\mathrm{el}$ is based on model which is presented in [01]. It is assumed that each dimension of sustainable development model is connected to considered factor of quality of life.

\section{Sustainable development concept}

Sustainable development can be defined as the process of meeting the needs of current and future generations without undetermining the resilience of the life-supporting properties of nature and integrity and security of social systems. Definition of this concept which is widely used in the literature is presented in [11] so that "development that is going to meet the needs of the present so as not to jeopardize the ability of future generations to meet their own needs". According to these definitions, sustainability means the adjustment of economic growth and development with the interests of environmental protection and social development. The social dimension of sustainability is based on the fact that equality and understanding of the interdependence of people within the community are the basic prerequisite for an acceptable quality of life, which is the first goal of development [15].

In the literature, different terms that are synonymous with dimensions of sustainable development are frequently used, for example indicators of sustainable development, performance of sustainable of development, etc. In this paper, the term sustainable development dimension is used and it is defined in accordance with the established vision, policy and objectives of sustainable development [18]. These dimensions should refer to the degree of fulfillment of the established goals. There are numerous methodologies which have been developed for defining and measuring of sustainable development deminesions. It should be noted that developed sustainable development dimensions at the communal services level should be comparable to dimensions of other local communities. Also, they allow the comparability outside the national borders. According to [03], in area of sustainable development 14 dimensions. In order to understand what can be expected in the future period in terms of quality of life in urban areas, it is necessary to accurately define dimensions of sustainable development. Respecting the quality of life, the dimensions of sustainable development are defined: political environment, natural environment, social environment and economic environment. Each dimension has own contentspecific. Respecting the recommendations from 
relevant literature [03], each developed sustainable dimension can be considered with respects to different aspects. For instance, activities and conditions aspect, sustainable problems aspects, scientific and technological solutions aspects, social, economic, political and regulatory solutions aspects are defined.

\section{Quality of life concept}

Quality of life is very complex and broad concept. According to many researchers that quality of life depended on the degree of achievement of objectives and lifestyle at the individual level. The quality of life is also the level of satisfaction obtained by man as a result of the consumption of goods and services, leisure activities and benefit from material and social conditions of the environment [8]. It has been considered that the quality of life, besides the two components, included a degree of satisfaction of financial resources, such as gross domestic product (GDP) and environmental protection [02]. According to the World Health Organization (WHO), the quality of life at the individual level is defined as the individual perception of the position individuals have in their lives, respecting the culture and value system in an environment in which the individuals live. It should be noted that the term quality of life at the individual level includes the quality of all life and not just some of its parts. The quality of life is defined as the subjective feeling of well-being and includes physical, psychological, social and economic dimensions [09]. Cummins [05] believes that there are seven dimensions of quality of life that should be considered: material well-being, health, productivity, intimacy, security, unity and emotional well-being. Three dimensions of the quality of life were defined: psychological and moral, socio-cultural and technical and economic. Arsovski et al. [01] suggest that quality of life has two components: (1) objective conditions which are explained as the resources that a person has, including the real opportunities to use these resources to meet one's needs, and (2) subjective experience of one's capabilities and the fulfillment of these needs. Objective factors usually reflects material prosperity, social factors are measured by means of social services and available infrastructure, and in the framework of subjective factors it shows some ephemeral characteristics, for example, mental feelings of units, satisfaction and happiness [16].
Depending on the aim and purpose of the research and existing concepts, measuring the quality of life is different. Nowdays, there are two opposed concepts; one concept is based on scientific settings and globalism. The second concept takes place at high ethical cosmic civilization. New knowledge and new technologies opened enormous possibilities for the development of the human community [15]. The subjective and objective approach to evaluation the quality of life is defined in [04].

The objective approach means using the certain standards in order to determine the quality of life. For example, increasing the level of work quality within its safety can be achieved by implementing standards such as OHSAS or ISO 22000. Respecting to results of good practice, the standardized management systems implemented by different organization systems will positively influence the people's quality of life. The main lack of these standards is defined by small number of people and is based on their assessment of aspects that should be satisfied in order to satisfy the needs of a great number of people. The subjective approach in measuring of the quality of life which includes the sense of well-being and personal prosperity; objective element was understood according to the circumstances that represent a good opportunity for exploitation by people while living their lives. It is highly defined by the character traits of individuals and their expectations, so the level of quality of life cannot be concluded based on these indicators. Diener and Suh [6] suggest that, at the same time, both concepts should be taken into consideration in determining the quality of life.

\section{THE PROPOSED MODEL}

The proposed model can be realized through following steps which are presented.

Step 1. In general, communal services is a complex sector that includes: the electricity supply, the controlling the waste water, the water supply, the public transport, the stationary traffic, maintenance of the existing green areas in the city, etc. Formally, sustainable development of communal services in urban areas is presented by set $1=\left\{\mathrm{x}_{1}, \ldots, \mathrm{x}_{\mathrm{i}}, \ldots, \mathrm{x}_{\mathrm{I}}\right\}$. The total number of elements is denoted as I. The $i, i=1, . ., I$ is index of sustainable development dimension. In this paper, sustainable development of communal services is presented through its crucial dimensions: political 
environment, natural environment, social environment, and economic environment. These dimensions of sustainable development in communal services sector are further concisely explained. Political environment presents political stability which is determined based on the number of adverse events that occurred in a period of one year. Natural environment values should be described as material well-being of customers. The social environment values are determined by satisfaction with the work of the Church community, the existence of sports and cultural events and the recreation facilities. Economic environment values depend on the level of income per family member and the value of inflation level in certain period.

Step 2. The big population growth in cities leads to an increase of significance of the evaluation problem and management of quality of life in cities. The quality of life is a multidimensional concept that includes physical, emotional, mental, behavioral and social components [12]. If the quality of life is viewed from different dimensions, all these dimensions must be considered at the same time [10]. The main problem in evaluating and determining the quality of life is the existence of many definitions according to which the evaluation of the life quality is determined. Depending on the aim and purpose of the research, measuring the quality of life is different. In this paper, the quality of life value at the individual level is assessed by customers respecting the following definition: Quality of life is defined as the interaction of human needs and the subjective perception of their fulfillment, mediated by the opportunities available to meet the needs [01].

Step 3 . The rating of the quality of life is given by survey. Respondents were citizens who are between 18 to 70 years old. Some of them are employed, students, retired and unemployed people. A set of citizens who participated in the survey is determined in a random manner without repeating. They were previously informed about the purpose and the content of the survey and agreed to participate in the research. Formally, they can be presented by set of indices $\varepsilon=\{1, \ldots, \mathrm{e}, . ., \mathrm{E}\}$. The total number of customers is denoted as $\mathrm{E}$. The index of customer is denoted as $e, e=1, . ., E$.

Step 4. Rating of the relative importance of sustainable development dimensions is performed by local government body. It bases its assess- ment on results of good practice in big cities of developed countries. Assessments of decision maker and customers are mapped into common measurement scales. The value 1 , i.e. the value 9 denotes that the relative importance of domain $x_{i}=1, . .$, I over $x_{i,},{ }^{\prime}=1, \ldots, l ; i \neq i^{\prime}$ is equal, i.e. extremely important, respectively. Similarity, values of sustainable development dimensions and quality of life should be explanted.

Step 5. It can be considered that discussed sustainable development dimensions don't have the same relative importance and as such can be set by using the comparison matrix pairs of relative importance. The elements of this matrix can be defined as the relative importance of the sustainable development domain $\mathrm{x}_{\mathrm{i}}, \mathrm{i}=1, \ldots, \mathrm{I}$ towards the sustainable development domain $x_{i}, i^{\prime}=1, \ldots, l ; i \neq i^{\prime}$. The relative importance of each pair of discussed sustainable development dimensions is carried out by decision makers who come from local governments.

The pair-wise comparison matrix of the relative importance of sustainable development dimensions which influence the life quality is positive and reciprocal to the main diagonal. It can be considered that decision maker can make mistakes in assessment. Therefore, it is necessary to determine the consistency of the assessment of decision maker. In the literature, there are numerous methods that determine the consistency of assessment [17] for example: the logarithmic deviation, the geometric means and the eigenvalue vector. The eigenvalue vector is widely used in the papers that can be found in the literature. Many authors believe that it represents a natural measure of consistency. By applying the eigenvalue vector, the index of consistency (C.I.) is calculated according to the expression:

$$
\text { C.I.=C.R./R.I. }
$$

Where:

C.R. is the index of consistency therefore, C.R. $=\frac{\lambda_{\max }-n}{n-1}$ is the eigenvalue of the pair-wise comparison matrix of the relative importance of the sustainable development dimensions dimension of the considered matrix is marked as $\mathrm{n}$ R.I. is an index which depends on matrix dimension. If C.I. is less than 0.1 , it can be considered that errors in the assessment of decision maker are acceptable and do not affect the final result. Otherwise, it is essential that decision maker carry 
out re-assessment of the relative importance of each pair of discussed sustainable development dimensions.

Weights vector of sustainable developmentdimensions is calculated according to the expression:

$A$ is the pair-wise comparison matrix of the relative importance of sustainable development dimensions e is a unit vector.

The eigenvalue of the pair-wise comparison matrix of relative importance of discussed sustainable development dimensions is obtained by solving the matrix equation:

$$
\mathrm{W} \cdot \lambda_{\max }=\mathrm{w} \cdot \mathrm{A}
$$

When consistency is achieved, then the weights vectorcanberepresented by the matrix ofcolumns:

$$
\mathrm{W}=\left[\mathrm{W}_{1}, \ldots, \mathrm{w}_{\mathrm{i}}, \ldots, \mathrm{W}_{\mathrm{I}}\right]_{1 \mathrm{xI}}
$$

Step 6. The weighted values of sustainable development dimensions can be calculated as:

$$
\mathrm{d}_{\mathrm{i}}^{\mathrm{e}}=\mathrm{w}_{\mathrm{i}} \cdot \mathrm{v}_{\mathrm{i}}^{\mathrm{e}} \mathrm{i}=1, \ldots, \mathrm{I} ; \mathrm{e}=1, . ., \mathrm{E}
$$

Where

$v_{i}^{e}$ is assessed value of sustainable development domain by customer $\mathrm{e}, \mathrm{i}=1, \ldots, \mathrm{I} ; \mathrm{e}=1, \ldots, \mathrm{E}$

Step 7. The linear multi-regression model is stated as:

$$
\mathrm{y}=\mathrm{a}_{0}+\sum_{\mathrm{i}=1}^{\mathrm{I}} \mathrm{a}_{\mathrm{i}} \cdot \mathrm{d}_{\mathrm{i}}^{\mathrm{e}}
$$

Where:

$a_{0}, a_{i}, i=1, \ldots, I$ are the coefficients of the linear multi-regression model

Step 8. By using the SPSS v21 IBM statistical software, the linear dependence between sustainable development dimensions and quality of life is given. Also, strength of the correlations between the analyzed dimensions of sustainable development and quality of life, $r_{i}, i=1, \ldots, \mid$ are determined.

Step 9. Based on the obtained data, it is possible to determine the strategies which can improve the performances of sustainable development dimensions which have the greatest impact on the quality of life in urban areas.

\section{THE ILLUSTRATIVE EXAMPLE}

Rapid and constant changes that are occurring in the world, lead to an increased significance of sustainable development in all areas of business and at the all levels. The rapid increasement of population number in large cities leads to the increasment of importance of assessment problem and monitoring level of sustainable development in the communal services sector. On other hand, citizens' satisfaction with the quality of communal services is one of the important factors affecting the level of quality of life in the big cities. The strength of the correlation between sustainable development dimensions and quality of life is determined by the proposed model with real life data. According to the obtained results, the improvement strategies should be defined.

The pair-wise comparison matrix of the relative importance of considered sustainable development dimensions is presented:

$$
\left[\begin{array}{cccc}
1 & 6 & 4 & 7 \\
1 / 6 & 1 & 1 / 3 & 2 \\
1 / 4 & 3 & 1 & 4 \\
1 / 7 & 1 / 2 & 1 / 4 & 1
\end{array}\right]
$$

By using the procedure (Step 3 of the proposed model), value of the index of consistency is calculated. This value is 0.0806 . It can be assumed, that the errors made in assessment of the relative importance of sustainable development dimensions are acceptable.

The weights vector is calculated by using Eq. (2) and can be presented by Eq. (4):

$$
\mathrm{W}=\left[\begin{array}{llll}
0.61, & 0.10, & 0.23, & 0.06
\end{array}\right]
$$

By using Eq. (5) the weighted values of sustainable development dimensions are given. These values and the assessed value of quality of life are presented in Table 1.

By using the procedure for determining multiple regression models [13], regression dependence between sustainable development dimensions and quality of life factors (analogy by Eq. 6) is given in Table 2.

So, that:

$y=3.621+0.254 \cdot x_{1}+0.674 \cdot x_{2}+1.317 \cdot x_{3}-3.799 \cdot x_{4}$

By using the SPSS v21 IBM statistical software (Step 8 of the proposed model), the correlation coefficients values are given (Table 3 ). 
Table 1: Input data for linear multiple regression model

\begin{tabular}{|c|c|c|c|c|}
\hline & $\begin{array}{c}\text { Political } \\
\text { environment }\end{array}$ & $\begin{array}{c}\text { Natural } \\
\text { environment }\end{array}$ & $\begin{array}{c}\text { Social } \\
\text { environment }\end{array}$ & $\begin{array}{l}\text { Economic } \\
\text { environment }\end{array}$ \\
\hline$e=1$ & 0.7 & 0.3 & 0.69 & 3.65 \\
\hline$e=2$ & 0.6 & 0.3 & 0.69 & 1.82 \\
\hline$e=3$ & 0.5 & 0.36 & 0.69 & 1.22 \\
\hline$e=4$ & 0.6 & 0.24 & 0.92 & 2.88 \\
\hline$e=5$ & 0.8 & 0.18 & 1.38 & 4.27 \\
\hline$e=6$ & 0.6 & 0.3 & 1.15 & 1.82 \\
\hline$e=7$ & 0.5 & 0.24 & 1.15 & 3.05 \\
\hline$e=8$ & 0.4 & 0.36 & 0.92 & 3.65 \\
\hline$e=9$ & 0.4 & 0.42 & 0.69 & 1.82 \\
\hline$e=10$ & 0.5 & 0.18 & 0.69 & 2.88 \\
\hline$e=11$ & 0.6 & 0.36 & 0.23 & 2.88 \\
\hline$e=12$ & 0.4 & 0.3 & 1.15 & 1.22 \\
\hline$e=13$ & 0.7 & 0.24 & 0.69 & 3.05 \\
\hline$e=14$ & 0.6 & 0.3 & 0.69 & 2.88 \\
\hline$e=15$ & 0.5 & 0.3 & 1.15 & 3.05 \\
\hline$e=16$ & 0.5 & 0.36 & 0.92 & 1.82 \\
\hline$e=17$ & 0.7 & 0.18 & 1.15 & 4.88 \\
\hline$e=18$ & 0.3 & 0.42 & 0.46 & 1.22 \\
\hline$e=19$ & 0.4 & 0.42 & 0.46 & 1.82 \\
\hline$e=20$ & 0.4 & 0.36 & 0.69 & 2.88 \\
\hline$e=21$ & 0.4 & 0.3 & 0.69 & 2.88 \\
\hline$e=22$ & 0.6 & 0.24 & 0.92 & 3.05 \\
\hline$e=23$ & 0.4 & 0.36 & 0.69 & 1.82 \\
\hline$e=24$ & 0.7 & 0.18 & 1.15 & 2.88 \\
\hline$e=25$ & 0.6 & 0.24 & 1.15 & 3.05 \\
\hline$e=26$ & 0.7 & 0.18 & 0.69 & 1.82 \\
\hline$e=27$ & 0.4 & 0.24 & 1.38 & 0.61 \\
\hline$e=28$ & 0.7 & 0.36 & 1.15 & 3.05 \\
\hline$e=29$ & 0.8 & 0.18 & 1.15 & 3.65 \\
\hline
\end{tabular}

Table 2. Coefficients of regression line

\begin{tabular}{|c|c|c|c|c|c|c|}
\hline \multirow{2}{*}{\multicolumn{2}{|c|}{ Model }} & \multicolumn{2}{|c|}{ Unstandardized Coefficients } & \multirow{2}{*}{$\frac{\text { Standardized Coefficients }}{\text { Beta }}$} & \multirow[t]{2}{*}{$\mathrm{t}$} & \multirow[t]{2}{*}{ Sig. } \\
\hline & & $B$ & Std. Error & & & \\
\hline \multirow[t]{5}{*}{1} & (Constant) & 3.621 & 1.881 & & 1.925 & - \\
\hline & political environment & .254 & .232 & .204 & 1.093 & .285 \\
\hline & natural environment & .674 & 1.997 & .076 & .338 & .738 \\
\hline & social environment & 1.317 & .778 & .311 & 1.694 & .103 \\
\hline & economic environment & -3.799 & 3.160 & -.261 & -1.202 & .241 \\
\hline
\end{tabular}


Table 3: Correlation correlations

\begin{tabular}{|l||c|c|c|c|c|}
\hline & $\begin{array}{c}\text { Political } \\
\text { environment }\end{array}$ & $\begin{array}{c}\text { Natural } \\
\text { environment }\end{array}$ & $\begin{array}{c}\text { Social } \\
\text { environment }\end{array}$ & $\begin{array}{c}\text { Economic } \\
\text { environment }\end{array}$ & $\begin{array}{c}\text { Quality of } \\
\text { life }\end{array}$ \\
\hline political environment & 1 & .595 & .373 & -.484 & .491 \\
\hline natural environment & & 1 & .507 & -.680 & .533 \\
\hline social environment & & & & -.565 & .573 \\
\hline economic environment & & & & 1 & -.587 \\
\hline quality of life & & & & & 1 \\
\hline
\end{tabular}

\section{DISCUSSION}

Based on the calculated values of the correlation coefficients, it can be concluded that all considered sustainable development dimensions have almost equal impact to quality life in communal services sector. This influence can be described as moderate correlation. Comparing of calculated values of correlation coefficients it can be concluded that environment dimension has somewhat greater impact on quality of life and the impact of these dimensions is negative $(-0.587)$. This further means that if the value of economic environment is getting higher, than the level of quality of life is getting lower. The obtained result was expected due to the defined structure of economic environment. Improvement of quality of life in urban areas primarily can be achieved if the gross national income is increased and the value of inflation is reduced over time. These strategies are defined at the state level, and it can be said that managers of communal services and local governments do not participate decision making process in economic environment dimension. The lowest impact to quality of life has got political environment dimension. It can be said that is obtained result is expected. The proposed model is tested on real life data which come from middle big cities from Serbia. According to evidence data, it is known that number of adverse events that occurred in a period of one year is not large. It is obvious that the improvement of quality of life in considered cities can be achieved by applying strategies which will lead to improvement of social environment and natural environment in communal services sector. Defining and applying of these strategies depend on managers of communal services. The improvement strategies of social environment may be: improvement of city transport; improvement of stationary transport; increasing and maintaining the city's green areas; new waste management strategies, etc. Improvement of natural environ- ment values should be achieved by developing improved production technology and distribution of electricity and wather. These objectives can be achieved through the reduction of losses of these communal services. Also, construction of recycling centers, among other things leads to a reduction in production costs of energy. The development of renewable energy sources at the national level and the ability to use the obtained energy is one of the strategies that will improve natural environment, which is further propagated to the improvement of quality of life.

The strength of the connections among considered sustainable development dimensions are calculated. It can be concluded that the economic environment dimension is in high correlations with other dimensions of sustainable development. At first glance, this result may seem illogical, however as sustainable development is considered within comunal sevices system in urban areas, and as it exists in the free market which is based on the principles of free capitalism, the obtained result is correct. This claim is based on the fact that the economy of mass production is in conflict with the goals of sustainable development. Correlations among political environment, natural environment and social environment are positive and may be described as moderate. The obtained result indicates that the application of appropriate strategies to improve for example political environment, leads to an improvement of natural environment and social environment. Similarly, in the same manner natural environment and social environment may be observed.

\section{CONCLUSION}

This paper work develops an extended regression model for evaluation the strength of the relationships between the sustainable development dimensions that affect the quality of life in urban areas. The relative importance of the sustainable 
development dimensions is stated by pair-wise comparison matrix analog to AHP method. The consistency of the assessment of decision-maker is determined by applying the method of eigenvalue vector. The values of these sustainable development dimensions and quality of life were determined at individual level. Manager in local government and customers map their assessments to a common measurement scale. The weighted value of each sustainable development domain is calculated as product the weight and its assessed value.

The extended linear multiple regression model was set. The dependent variable was defined as the quality of life at the level of an individual. The value of the coefficients of correlation between the identified sustainable development dimensions and the quality of life at the level of a group in urban areas can be determined by using the standard statistical program. Respecting the obtained values of the coefficients of correlation, the strategies for improving the performances of sustainable development dimensions that lead to increased sustainability of society in urban areas can be defined.

\section{REFERENCE}

1) Arsovski, S., Putnik, G., Moljević, S., Đurović, D. (2016) Sustainable quality of life: is it possible in transition economics?. First International conference on Quality of Life (S. Arsovski, D. Tadić, M. Stefanović, Eds.), 107-122. Center for Quality, Faculty of Engineering, University of Kragujevac.

2) Arsovski, S., Milićević, R. (2010) Management of business continuity and quality of life. Kragujevac: Center for Quality, Faculty of Engineering, University of Kragujevac.

3) Choucri, N. (2007) Mapping Sustainability: Knowledge e-Networking and the value chain. New York City, USA: Springer.

4) Christoph, B., Noll, H.H. (2003) Subjective WellBeing in the European Union During the 90s. Social Indicators Resrarch Series, 18, 197-222.

5) Cummins, R.A. (2000) Objective and subjective auality of life: An interactive model. Social Indicators Resrarch Series, 52(1), 55-72.

6) Diener, E., Suh, E. (1997) Measuring quality of life: Economic, social, and subjective indicators. Social Indicators Resrarch Series, 40(1-2), 189-216.
7) Garvare, R., Johanson, P. (2010) Management for Sustanaibility-A stakeholder Theory. Total Quality Management \& Busoness Exellence, 21(7-8), 737-744.

8) Goranczewski, B., Puciato, D. (2010) TQM and quality of life. Quality Problems, 6, 4-9.

9) Haas, B.K. (1999) Clarification and integration of similar quality of life concepts. Image: The Journal of Nursing Scholarship, 31(3), 215-220.

10) Hagerty, M. R., Cummins, R. A., Ferriss, A. L., Land, K., Michalos, A. C., Peterson, M., Sharpe, A., Sirgy, M.J. Vogel, J. (2001) Quality of Life Indexes for National Policy: Review and Agenda for Research. Social Indicators Resrarch Series, 55(1), 1-96.

11) http://www.un-documents.net/wced-ocf.htm (1987) World Commission on Environmental and Sustainability.

12) Janse, A.J., Gemke, R.J., Uiterwaal, C.S., Tweel, I., Kimpen, JL., Sinnema, G. (2004) Quality of Life: Patients and Dont Always Agree: a Meta-Analysis. Journal of Clinical Epidemiology, 57(7), 653-714.

13) Mason, R., Lind, D., Marchal, W. (1999) Statistical techniques in business and economics. Boston, Mass.: Irwin/McGraw Hill.

14) Mc Manus, S.T. (2008) Organizational Resilience in New Zealand, PhD Thesis. Canterbury: University of Canterbury.

15) Milivojevic, J., Stojanović, S. Kokić-Arsić, A. (2016) Quality of life between centuries. First International conference on Quality of Life (S. Arsovski, D. Tadić, M. Stefanović, Eds.), 347352. Center for Quality, Faculty of Engineering, University of Kragujevac.

16) Nowicki, P., (2016) Selected standardized management systems vs quality of life. First International conference on Quality of Life (S. Arsovski, D. Tadić, M. Stefanović, Eds.), 367374. Center for Quality, Faculty of Engineering, University of Kragujevac.

17) Saaty, T.L., (1990) How to Make a Decision: The Analytic Hierarchy Process. European Journal Operational Research, 48, 9-26.

18) Vos, R. (2008) Defining sustainability: a conceptual orientation. Jurnal of Chemical Technology and Biotechnology, 8, 334-339.

Paper sent to revision: 09.07.2016.

Paper ready for publication: 24.11.2016. 